\title{
Effectiveness of Traditional Chinese Exercise for Symptoms of Knee Osteoarthritis: A Systematic Review and Meta-Analysis of Randomized Controlled Trials
}

\author{
Ruojin Li ${ }^{1,+}\left(\mathbb{D}\right.$, Hongwei Chen ${ }^{2,3,4,+} \mathbb{D}$, Jiahao Feng ${ }^{5}$, Ying Xiao ${ }^{2,3}$, Haoyang Zhang ${ }^{6}$, \\ Christopher Wai-Kei Lam ${ }^{2,3, *}$ and Hong Xiao ${ }^{1, *}$ \\ 1 Department of Physical Education, Sun Yat-Sen University, Guangzhou 510000, China; \\ lirj33@mail2.sysu.edu.cn \\ 2 Faculty of Medicine, Macau University of Science and Technology, Taipa, Macau 999078, China; \\ musthwchen@gmail.com (H.C.); yxiao@must.edu.mo (Y.X.) \\ 3 State Key Laboratory of Quality Research in Chinese Medicines, Macau University of Science and \\ Technology, Avenida Wai Long, Taipa, Macau 999078, China \\ 4 School of Public Health (Shenzhen), Sun Yat-Sen University, Shenzhen 518000, China \\ 5 School of Medicine, Sun Yat-Sen University, Guangzhou 510000, China; fengjh27@mail2.sysu.edu.cn \\ 6 School of Data and Computer Science, Sun Yat-Sen University, Guangzhou 510000, China; \\ zhanghaoyang0@hotmail.com \\ * Correspondence: wklam@must.edu.mo (C.W.-K.L.); xiaoh8@mail.sysu.edu.cn (H.X.) \\ + Both authors have equal contributions to the paper.
}

Received: 7 October 2020; Accepted: 22 October 2020; Published: 27 October 2020

\begin{abstract}
Background: Growing evidences have advocated the potential benefits of traditional Chinese exercise (TCE) on symptomatic improvement of knee osteoarthritis (KOA). However, most of them have been derived from cross-sectional studies or case reports; the effectiveness of TCE therapies has not been fully assessed with a randomized control trial (RCT). In order to evaluate the combined clinical effectiveness of TCE for KOA, we conducted a systematic review and meta-analysis on the existing RCTs on KOA. Methods: A systematic search was performed in four electronic databases: PubMed, Web of Science, Cochrane Library, and EMBASE from the time of their inception to February 2020. All eligible RCTs were included in which TCE was utilized for treating KOA as compared to a control group. Two reviewers independently extracted the data and evaluated the risk of bias following the Cochrane Risk of Bias Tool for RCT. The symptoms of KOA evaluated by the Western Ontario and McMaster Universities Arthritis Index (WOMAC) and the Knee Injury and Osteoarthritis Outcome Score (KOOS) were regarded as the primary outcomes in this study. Each outcome measure was pooled by a standardized mean difference (SMD) with $95 \%$ confidence intervals (CI). A meta-analysis was applied with a random or fixed effect model for the collected data to calculate the summary SMD with 95\% CI based on different statistical heterogeneity. In addition, subgroup analyses were used to investigate heterogeneity and sensitivity analysis was carried out for the results of the meta-analysis. Egger's test and the funnel plots were used to examine the potential bias in the RCTs. Results: A total of 14 RCTs involving 815 patients with KOA were included. Compared with a control group; the synthesized data of TCE showed a significant improvement in WOMAC/KOOS pain score (SMD $=-0.61 ; 95 \% \mathrm{CI}:-0.86$ to $-0.37 ; p<0.001$ ), stiffness score (SMD $=-0.75 ; 95 \% \mathrm{CI}:-1.09$ to $-0.41 ; p<0.001)$, and physical function score (SMD $=-0.67 ; 95 \%$ CI: -0.82 to $-0.53 ; p<0.001)$. Conclusions: Our meta-analysis suggested that TCE may be effective in alleviating pain; relieving stiffness and improving the physical function for patients with KOA. Yet; given the methodological limitations of included RCTs in this meta-analysis; more high-quality RCTs with large sample size and long-term intervention are required to further confirm the effectiveness and underlying mechanisms of TCE for treating KOA.
\end{abstract}


Keywords: traditional chinese exercise; tai chi; baduanjin; knee osteoarthritis (KOA); systematic review; meta-analysis

\section{Introduction}

Knee osteoarthritis (KOA) is a kind of degenerative knee-joint disease, which is also a leading cause of disability accounting for $9.6 \%$ men and $18.0 \%$ women aged over 60 years [1]. As a degenerative and progressive knee-joint disease, the development of KOA is closely associated with multiple factors, including demographic factors such as age, over-weight, and sex, and sport injuries factors such as muscle weakness, joint laxity, and bone trauma [2]. Since KOA causes disability and impacts on the patient's quality of life, it has become a major public health issue worldwide [3]. In addition to the surgical treatment involving joint reconstruction, other treatments of KOA can be broadly categorized as pharmacological and non-pharmacological $[4,5]$. Although the pharmacological treatment can be effective for reducing pain and improving physical function in KOA [6-8], more and more research studies have shown that the long-term usage of medicines and intra-articular injection may cause adverse effects such as gastrointestinal reaction, multi-organ failure, pain, and swelling [9-12]. Moreover, surgery and a long-term pharmacological treatment may cause a great impact on society and individuals with enormous health-care expenditures and reduction in the quality of life $[13,14]$.

In contrast, non-pharmacological interventions including physical, psychological, and mind-body exercises are relatively safe and effective [15]. They have been strongly recommended by the Osteoarthritis Research Society International (OARSI), the American College of Rheumatology (ACR), and the American Academy of Orthopedic Surgeons (AAOS) $[4,16,17]$. Overall, a non-pharmacological intervention may be an important option for either the society or patients.

Traditional Chinese exercise (TCE), as a therapeutic, aerobic, and mind-body exercise originated from traditional Chinese medicine tracing back to approximately three thousand years ago [18-20]. TCE, as a major integral part of non-pharmacological intervention, includes Tai Chi, Baduanjin, Yijinjing, and Wuqinxi that are characterized by slow, gentle, and symmetrical movements, musculoskeletal stretching, physical and psychological relaxation, combined with deep diaphragmatic breathing [21-24]. Increasing research and practices have demonstrated that TCE is effectively beneficial for improving physical status and modulating the psychological health of patients with mental disorders [21], metabolic syndrome [24], Parkinson's disease [25], post-myocardial infarction [26], chronic obstructive pulmonary disease [27], type 2 diabetes mellitus [28], chronic pain disease [29], and cancer [30]. TCE is also beneficial for limb rehabilitation which includes limb motor function, balance function, daily life activities, and neurological improvement [31].

Currently, increasing numbers of clinical trials and meta-analyses have reported that TCE has been used for treating KOA [18,22,32-35]. More and more RCTs have indicated that TCE can significantly improve the symptoms of KOA including pain reduction, relief of stiffness, and improvement on physical function [33-35]. However, results of different trials are inconsistent, with several trials suggesting that TCE had no effects on those outcomes probably due to the small sample size, short duration time, and the severity of KOA in participants [36,37]. The conclusions from current studies have remained controversial. Moreover, a previous systematic review and meta-analysis has demonstrated that TCE can significantly improve symptoms of KOA, but it has insufficient subgroup analysis and included ineligible studies [18]. Therefore, it is appropriate to further investigate the effectiveness of TCE for patients with KOA, aiming to help doctors and other health-care professionals plan stage-specific treatment for patients.

\section{Methods}

This systematic review and meta-analysis was reported in accordance with the Preferred Reporting Items for Systematic Reviews and Meta-Analyses (PRISMA) guidelines [38]. 


\subsection{Search Strategy}

A literature search was conducted by two independent researchers (R.L. and H.C.). The systematic search of data was performed in four electronic databases: PubMed, Web of Science, Cochrane Library, and EMBASE to identify effects of TCE on symptoms of KOA. We included papers published from the time of their inception to February 2020 in English with the following keywords: \{(Traditional Chinese exercise [Title/Abstract] OR "Tai Chi" [Title/Abstract] OR "Qigong" [Title/Abstract] OR Yijinjing [Title/Abstract] OR Baduanjin [Title/Abstract] OR Wuqinxi" [Title/Abstract]) AND ("knee osteoarthritis" [Title/Abstract] OR "knee arthritis" [Title/Abstract] OR gonitis [Title/Abstract] OR gonarthritis [Title/Abstract]) AND ("randomized controlled trial" [Title/Abstract] OR randomization [Title/Abstract] OR randomized [Title/Abstract])\}. A more detailed search strategy is in the supplementary material (Table S1).

\subsection{Inclusion and Exclusion Criteria}

Articles were included for this research based on the following criteria: (i) The study design was a randomized controlled trial (RCT); (ii) participants were diagnosed with KOA by validated criteria, such as those of the American College of Rheumatology (ACR), the American Rheumatism Association (ARA), the Kellgren Lawrence classification (KL), radio-graphic evidence or physician-confirmed diagnosis [39-41]; (iii) outcome measures included the assessment of pain intensity, stiffness, and physical function for KOA using the Western Ontario and McMaster Universities Osteoarthritis Index (WOMAC), and the Knee Injury and Osteoarthritis Outcome Score (KOOS) [42,43]; (iv) the trial explored the efficacy of different traditional Chinese exercises, as compared with a control or comparison group (e.g., physical therapy, health education, sham exercise) on symptoms of KOA.

Articles were excluded based on the following criteria: (i) Those that were study-designed (not RCT); (ii) participants also had hip osteoarthritis; and (iii) the article was retracted.

\subsection{Study Selection}

After a systematic search, the retrieved articles were screened for eligibility based on the above inclusion and exclusion criteria by two independent reviewers (R.L. and H.C.) to confirm that the title and abstract conformed with the criteria. Then, the potentially eligible articles were further read in full text for assessment. Discrepancies were resolved by the third reviewer (J.F.).

\subsection{Data Extraction}

Three reviewers (R.L., H.C., and J.F.) independently rated the included paper and extracted the data. Details of the retrieved articles are summarized in Table 1. The following data were extracted from the retrieved articles: (i) Reference (first author and year of publication); (ii) study location; (iii) characteristics of participants; (iv) intervention protocol; (v) outcomes measure; and (vi) adverse effects [44].

\subsection{Risk of Bias Assessment in Individual Trials}

Two reviewers (R.L. and H.C.) independently evaluated the risk of bias using the following criteria adopted from the Cochrane Risk of Bias Tool for Randomized Controlled Trials: Selection bias, performance bias, attribution bias, reporting bias, and other bias. The classification of risk of bias was divided into "Low risk of bias", "High risk of bias", or "unclear" [45]. Disagreements were resolved by a third reviewer (J.F.). The extent of agreement between the reviewers was calculated using the Kappa coefficient $(\mathrm{k}=0.908)$.

\subsection{Statistical Analysis}

All statistical analyses were performed using the Review Manager 5 software (version 5.3, The Nordic Cochrane Centre, Copenhagen, Denmark). The symptoms of KOA were evaluated using 
the Western Ontario and McMaster Universities Arthritis Index (WOMAC) and the Knee Injury and Osteoarthritis Outcome Score (KOOS), which were regarded as the primary outcomes in this research. We extracted the quantitative data from all selected RCTs including sample size, as well as the mean and standard deviation of outcome measures at baseline and post-intervention in each group. For continuous outcomes with different scoring units, the standardized mean difference (SMD) with 95\% confidence intervals (CI) was used to pool each outcome measure for estimating the effect size. Statistical heterogeneity was evaluated using the $\mathrm{I}^{2}$ test to identify the difference in results, and was categorized as: (i) $\mathrm{I}^{2} \leq 25 \%$, low heterogeneity; (ii) $25 \%<\mathrm{I}^{2}<50 \%$, moderate heterogeneity; (iii) $50 \%<\mathrm{I}^{2}<75 \%$, substantial heterogeneity; (iv) $\mathrm{I}^{2} \geq 75 \%$, high heterogeneity. A fixed-effect model was applied to evaluate the summary SMD with $95 \%$ CI when $\mathrm{I}^{2}<50 \%$ and $p>0.01$; otherwise, a random-effect model was applied [46,47]. In addition, subgroup analyses were used to investigate the heterogeneity involving the exercise type (Tai Chi and Baduanjin), geographical location (Asian populations and non-Asian populations), duration time (8 and 12 weeks), sample size (no. of participants $\geq 30$ and $<30$ ), and control group type (active control group and passive control group). Sensitivity analysis was carried out for the results of the meta-analysis, which included the outcomes of pain, stiffness, and physical function using the WOMAC or KOOS score [46]. When the number of all included trials was $\geq 10$, Egger's test and the funnel plots were used to examine the potential bias in the RCTs included in this meta-analysis [45]. 
Table 1. Characteristics of data extracted from the included studies.

\begin{tabular}{|c|c|c|c|c|c|c|c|c|c|}
\hline \multirow[b]{2}{*}{ Reference } & \multirow[b]{2}{*}{$\begin{array}{c}\text { Study } \\
\text { Location }\end{array}$} & \multicolumn{3}{|c|}{ Participant Characteristics } & \multicolumn{3}{|c|}{ Intervention Protocol } & \multirow[b]{2}{*}{$\begin{array}{l}\text { Outcomes } \\
\text { Measure }\end{array}$} & \multirow[b]{2}{*}{$\begin{array}{l}\text { Adverse } \\
\text { Effects }\end{array}$} \\
\hline & & $\begin{array}{l}\text { Patients } \\
\text { Diagnostic } \\
\text { Criteria }\end{array}$ & $\begin{array}{l}\text { Sample Size } \\
\text { (IG/CG) }\end{array}$ & $\begin{array}{l}\text { Mean Age or } \\
\text { Age Range }\end{array}$ & Intervention Group & Control Group & $\begin{array}{c}\text { Duration } \\
\text { Time }\end{array}$ & & \\
\hline $\begin{array}{l}\text { AN et al., } \\
2008 \text { [48] }\end{array}$ & $\begin{array}{c}\text { Shanghai, } \\
\text { China }\end{array}$ & ACR & $11 / 10$ & $\begin{array}{l}\text { IG: } 65.4 \pm 8.2 \\
\text { CG: } 64.6 \pm 6.7\end{array}$ & $\begin{array}{c}\text { Baduanjin } \\
5 \times 30 \mathrm{~min} / \text { week }\end{array}$ & None & 8 weeks & $\begin{array}{c}\text { WOMAC } \\
\text { a. Pain } \\
\text { b. Stiffness } \\
\text { c. Physical function }\end{array}$ & $\begin{array}{c}\text { No adverse } \\
\text { event }\end{array}$ \\
\hline $\begin{array}{c}\text { Brisme'e et al., } \\
2007 \text { [49] }\end{array}$ & Texas, USA & ARA & $18 / 13$ & $\begin{array}{l}\text { IG: } 70.8 \pm 9.8 \\
\text { CG: } 68.8 \pm 8.9\end{array}$ & $\begin{array}{c}\text { Tai Chi } \\
3 \times 40 \mathrm{~min} / \text { week }\end{array}$ & $\begin{array}{l}\text { Attention control } \\
\text { pre- } 6 \text { weeks } \\
3 \times 40 \text { min/week } \\
\text { post } 6 \text { weeks } \\
\text { no attend activity }\end{array}$ & 12 weeks & $\begin{array}{c}\text { WOMAC } \\
\text { a. Pain } \\
\text { b. Stiffness } \\
\text { c. Physical function }\end{array}$ & $\begin{array}{c}\text { No adverse } \\
\text { event }\end{array}$ \\
\hline $\begin{array}{l}\text { Lee et al., } \\
2009 \text { [36] }\end{array}$ & $\begin{array}{l}\text { Hwaseong, } \\
\text { Korea }\end{array}$ & KL scale & $29 / 15$ & $\begin{array}{l}\text { IG:70.2 } \pm 4.8 \\
\text { CG: } 66.9 \pm 6.0\end{array}$ & $\begin{array}{c}\text { Tai Chi } \\
2 \times 60 \mathrm{~min} / \text { week }\end{array}$ & None & 8 weeks & $\begin{array}{c}\text { WOMAC } \\
\text { a. Pain } \\
\text { b. Stiffness } \\
\text { c. Physical function }\end{array}$ & $\begin{array}{c}\text { No adverse } \\
\text { event }\end{array}$ \\
\hline $\begin{array}{l}\text { Li et al., } \\
2019 \text { [50] }\end{array}$ & Jining, China & $\begin{array}{c}\text { Radiographic } \\
\text { evidence }\end{array}$ & $54 / 53$ & $\begin{array}{l}\text { IG: } 69.6 \pm 4.3 \\
\text { CG: } 68.5 \pm 3.5\end{array}$ & $\begin{array}{c}\text { Tai Chi } \\
5 \times 45 \mathrm{~min} / \text { week }\end{array}$ & $\begin{array}{c}\text { Traditional physical } \\
\text { exercises } \\
5 \times 45 \mathrm{~min} / \text { week }\end{array}$ & 12 weeks & $\begin{array}{c}\text { WOMAC } \\
\text { a. Pain } \\
\text { b. Physical function }\end{array}$ & $\begin{array}{c}\text { No adverse } \\
\text { event }\end{array}$ \\
\hline $\begin{array}{l}\text { Michael et al., } \\
2013 \text { [37] }\end{array}$ & $\begin{array}{l}\text { Knoxville, } \\
\text { USA }\end{array}$ & ACR & $12 / 6$ & $\begin{array}{l}\text { IG: } 68.1 \pm 5.3 \\
\text { CG:70.5 } \pm 5.0\end{array}$ & $\begin{array}{c}\text { Tai Chi } \\
5 \times 60 \mathrm{~min} / \text { week }\end{array}$ & Not intervention & 10 weeks & $\begin{array}{c}\text { WOMAC } \\
\text { a. Pain } \\
\text { b. Stiffness } \\
\text { c. Physical function }\end{array}$ & $\begin{array}{c}\text { No adverse } \\
\text { event }\end{array}$ \\
\hline $\begin{array}{l}\text { Mona et al., } \\
2018 \text { [52] }\end{array}$ & Tehran, Iran & KL scale & $16 / 16$ & $\begin{array}{c}\text { IG:55.25 } \pm 5.72 \\
\text { CG:56.06 } \pm \\
6.13\end{array}$ & $\begin{array}{c}\text { Tai Chi } \\
12 \times 45 \mathrm{~min} / 4 \text { week } \\
\text { and Routin } \\
\text { physiotherapy } \\
12 \times 20 \mathrm{~min} / 4 \text { week }\end{array}$ & $\begin{array}{c}\text { Routine } \\
\text { physiotherapy } 12 \times \\
20 \mathrm{~min} / 4 \text { week }\end{array}$ & 4 weeks & $\begin{array}{c}\text { KOOS } \\
\text { a. Pain } \\
\text { b. Symptoms } \\
\text { c. Daily living }\end{array}$ & $\begin{array}{c}\text { No adverse } \\
\text { event }\end{array}$ \\
\hline $\begin{array}{l}\text { Song et al., } \\
2003 \text { [53] }\end{array}$ & Seoul, Korea & ACR & $22 / 21$ & $\begin{array}{l}\text { IG: } 64.8 \pm 6.0 \\
\text { CG:62.5 } \pm 5.6\end{array}$ & $\begin{array}{c}\text { Tai Chi } \\
\text { pre- } 2 \text { weeks } \\
3 \times 20 \mathrm{~min} / \text { week } \\
\text { post-10 weeks } \\
3 \times 20 \mathrm{~min} / \text { week }\end{array}$ & None & 12 weeks & $\begin{array}{c}\text { WOMAC } \\
\text { a. Pain } \\
\text { b. Stiffness } \\
\text { c. Physical function }\end{array}$ & $\begin{array}{c}\text { No adverse } \\
\text { event }\end{array}$ \\
\hline
\end{tabular}


Table 1. Cont.

\begin{tabular}{|c|c|c|c|c|c|c|c|c|c|}
\hline \multirow[b]{2}{*}{ Reference } & \multirow[b]{2}{*}{$\begin{array}{l}\text { Study } \\
\text { Location }\end{array}$} & \multicolumn{3}{|c|}{ Participant Characteristics } & \multicolumn{3}{|c|}{ Intervention Protocol } & \multirow[b]{2}{*}{$\begin{array}{l}\text { Outcomes } \\
\text { Measure }\end{array}$} & \multirow[b]{2}{*}{$\begin{array}{l}\text { Adverse } \\
\text { Effects }\end{array}$} \\
\hline & & $\begin{array}{l}\text { Patients } \\
\text { Diagnostic } \\
\text { Criteria }\end{array}$ & $\begin{array}{l}\text { Sample Size } \\
\text { (IG/CG) }\end{array}$ & $\begin{array}{l}\text { Mean Age or } \\
\text { Age Range }\end{array}$ & Intervention Group & Control Group & $\begin{array}{l}\text { Duration } \\
\text { Time }\end{array}$ & & \\
\hline $\begin{array}{l}\text { Song et al., } \\
2007 \text { [54] }\end{array}$ & Seoul, Korea & $\begin{array}{l}\text { Radiographic } \\
\text { evidence }\end{array}$ & $22 / 21$ & $\begin{array}{l}\text { IG: } 64.8 \pm 6.0 \\
\text { CG: } 62.5 \pm 5.6\end{array}$ & $\begin{array}{c}\text { Tai Chi } \\
\text { pre- } 2 \text { weeks } \\
3 \times 60 \mathrm{~min} / \text { week } \\
\text { post- } 10 \text { weeks } \\
3 \times 60 \mathrm{~min} / \text { week }\end{array}$ & None & 12 weeks & $\begin{array}{l}\text { WOMAC } \\
\text { a. Pain } \\
\text { b. Stiffness }\end{array}$ & $\begin{array}{l}\text { No adverse } \\
\text { event }\end{array}$ \\
\hline $\begin{array}{l}\text { Tsai et al., } \\
2012 \text { [55] }\end{array}$ & $\begin{array}{l}\text { Arkansas, } \\
\text { USA }\end{array}$ & $\begin{array}{l}\text { health care } \\
\text { provider }\end{array}$ & $28 / 27$ & $\begin{array}{c}\text { IG:78.89 } \pm 6.91 \\
\text { CG:78.93 } \\
8.30\end{array}$ & $\begin{array}{c}\text { Tai Chi } \\
3 \times 20-40 \mathrm{~min} / \text { week }\end{array}$ & $\begin{array}{c}\text { Attention control } \\
3 \times 20-40 \mathrm{~min} / \text { week }\end{array}$ & 20 weeks & $\begin{array}{c}\text { WOMAC } \\
\text { a. Pain } \\
\text { b. Stiffness } \\
\text { c. Physical function }\end{array}$ & $\begin{array}{c}\text { No adverse } \\
\text { event }\end{array}$ \\
\hline $\begin{array}{l}\text { Wang et al., } \\
2009 \text { [56] }\end{array}$ & Boston, USA & ACR & $20 / 20$ & $\begin{array}{l}\text { IG: } 63 \pm 8.1 \\
\text { CG: } 68 \pm 7.0\end{array}$ & $\begin{array}{c}\text { Tai Chi } \\
2 \times 60 \mathrm{~min} / \text { week }\end{array}$ & $\begin{array}{l}\text { Attention control } \\
2 \times 60 \mathrm{~min} / \text { week }\end{array}$ & 12 weeks & $\begin{array}{c}\text { WOMAC } \\
\text { a. Pain } \\
\text { b. Stiffness } \\
\text { c. Physical function }\end{array}$ & $\begin{array}{l}\text { One } \\
\text { participant in } \\
\text { the Tai Chi } \\
\text { group } \\
\text { reported an } \\
\text { increase in } \\
\text { knee pain }\end{array}$ \\
\hline $\begin{array}{l}\text { Ye et al., } \\
2020[34]\end{array}$ & Fujian, China & $\mathrm{ACR}$ & $25 / 25$ & $\begin{array}{c}\text { IG: } 64.48 \pm 7.81 \\
\text { CG: } 63.08 \pm \\
3.65\end{array}$ & $\begin{array}{c}\text { Baduanjin } \\
3 \times 40 \mathrm{~min} / \text { week }\end{array}$ & None & 12 weeks & $\begin{array}{c}\text { WOMAC } \\
\text { a. Pain } \\
\text { b. Stiffness } \\
\text { c. Physical function }\end{array}$ & $\begin{array}{c}\text { No adverse } \\
\text { event }\end{array}$ \\
\hline $\begin{array}{l}\text { Zhu et al., } \\
2016 \text { [35] }\end{array}$ & $\begin{array}{l}\text { Shanghai, } \\
\text { China }\end{array}$ & $\mathrm{ACR}$ & $23 / 23$ & $\begin{array}{c}\text { IG:64.61 } \pm 3.40 \\
\text { CG:64.53 } \pm \\
3.43\end{array}$ & $\begin{array}{c}\text { Tai Chi } \\
3 \times 60 \mathrm{~min} / \text { week }\end{array}$ & $\begin{array}{l}\text { Healthy education } \\
1 \times 60 \mathrm{~min} / \text { week }\end{array}$ & 24 weeks & $\begin{array}{c}\text { WOMAC } \\
\text { a. Pain } \\
\text { b. Stiffness } \\
\text { c. Physical function }\end{array}$ & $\begin{array}{c}\text { No adverse } \\
\text { event }\end{array}$ \\
\hline
\end{tabular}

Abbreviations: ACR: American College of Rheumatology; ARA: American Rheumatism Association; CG: Control Group; IG: Intervention Group; KL: Kellgren-Lawrence Scale; KOOS: The Knee injury and Osteoarthritis Outcome Score; WOMAC: The Western Ontario and McMaster Universities Osteoarthritis Index. 


\section{Results}

\subsection{Study Selection}

As shown in Figure 1, there were 265 articles identified through four different electronic database searches. Among them, 133 were duplicated and excluded. A total of 84 records of reviews, case reports, protocol, and commentary were excluded after screening the title and abstract. Then, full-texts of the remaining 48 articles were further assessed, and 34 full-text articles were excluded due to the following three reasons: Conference papers $(n=10)$; data duplication $(n=5)$; not meeting our inclusion criteria or meeting exclusion criteria $(n=19)$. Finally, a total of 14 RCTs were included in this meta-analysis.

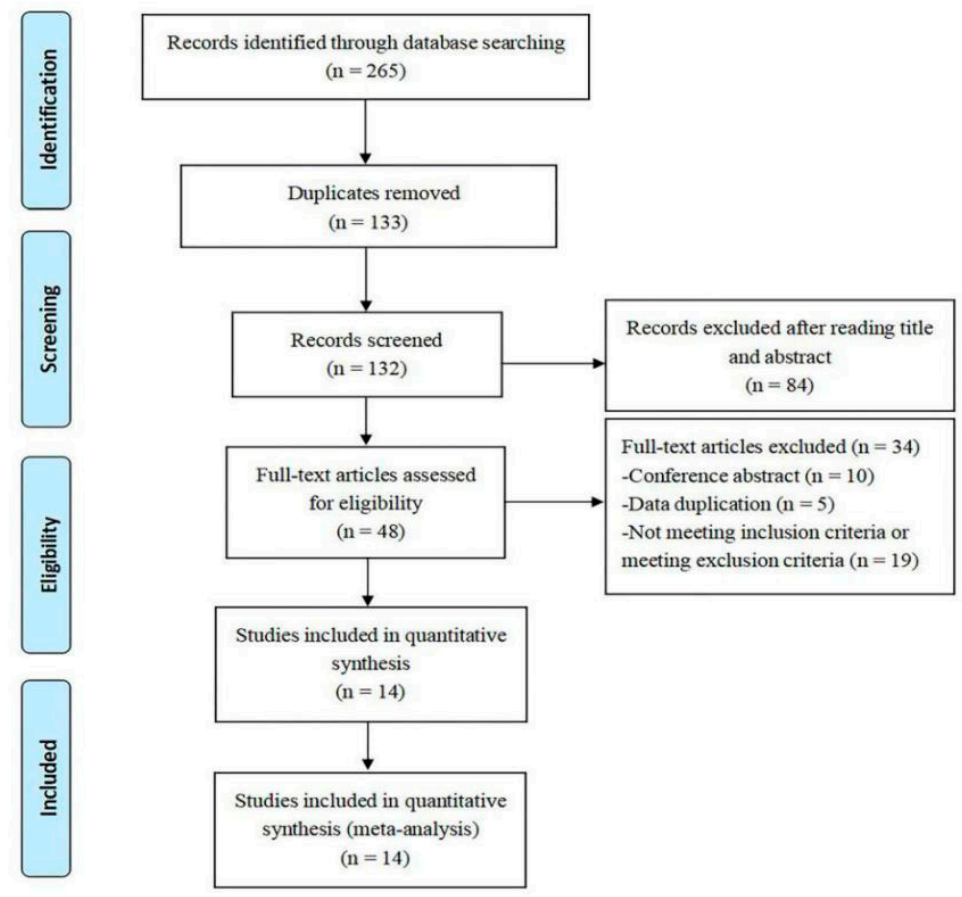

Figure 1. Flowchart of the studies selection process.

\subsection{Study Characteristics}

Characteristics of study location, participant data, intervention protocol, outcomes measured, and adverse effects from the assessed studies are summarized in Table 1.

Together, the 14 RCTs contained a total of 815 participants, and all were published in English before February 2020 [33-37,48-56]. The geographical location of the studies originated from China, Iran, USA, or Korea. Participants were diagnosed with KOA by the American College of Rheumatology classification criteria (ACR), the diagnostic criteria of the American Rheumatism Association (ARA), the Kellgren Lawrence classification (KL), radio-graphic evidence, or physician-confirmed.

For intervention programs, 11 studies applied the Tai Chi exercise [33,35-37,49,50,52-56] and two studies applied the Baduanjin exercise $[34,48]$. Only one study applied both the Tai Chi and Baduanjin exercise [51]. Of these studies, the duration time of interventions varied from 4 to 24 weeks. There were 12 studies that measured the symptoms of KOA using the Western Ontario and McMaster Universities Osteoarthritis Index (WOMAC). The WOMAC scale is a self-administered questionnaire consisting of 24 items divided into three sub-scales: Pain, stiffness, and physical function [42]. However, scoring of the WOMAC was reported differently among studies, with ten reporting on a scale of 0-100 [34-37,48-50,53-55] and two reporting on a scale score of 0-1700 [33,56], with higher scores reflecting a worse condition. In addition, two other studies used the Knee Injury and Osteoarthritis Outcome Score (KOOS) in order to measure the symptoms of KOA [51,52]. This is an extension 
of the WOMAC scale, which covers five patient-relevant dimensions: Pain, other disease-specific symptoms, activities of daily living function, sport and recreation function, and knee-related quality of life, with a score of zero representing extreme knee problems and a score of 100 representing no knee problems [43]. Finally, only one study reported adverse events and the remaining studies did not report any adverse events.

\subsection{Assessment of Risk of Bias}

Results of the assessment of risk of bias for all the included studies are summarized in Figures 2 and 3. With regard to the risk of selection bias, 10 of all the included studies in random sequence generation were at low risk $[33-36,49,50,53-56]$ and nine of all the included studies in allocation concealment were at low risk $[33-36,49,50,53,55,56]$, while the remaining studies were unclear mentioning only randomization without describing clearly their method of random sequence generation and allocation concealment, respectively $[37,48,51,52,54]$. Of these studies, only three studies were at low risk in the risk of performance bias $[33,35,49]$. For the risk of detection bias, eight studies were at low risk that adopted the blinding of outcome assessment $[33-36,49,53,55,56]$. Moreover, most of the studies were at low risk in the risk of attrition bias and reporting bias, only two studies were at high risk with no reported trial registration $[53,54]$. All the included studies were unclear in the risk of other bias.

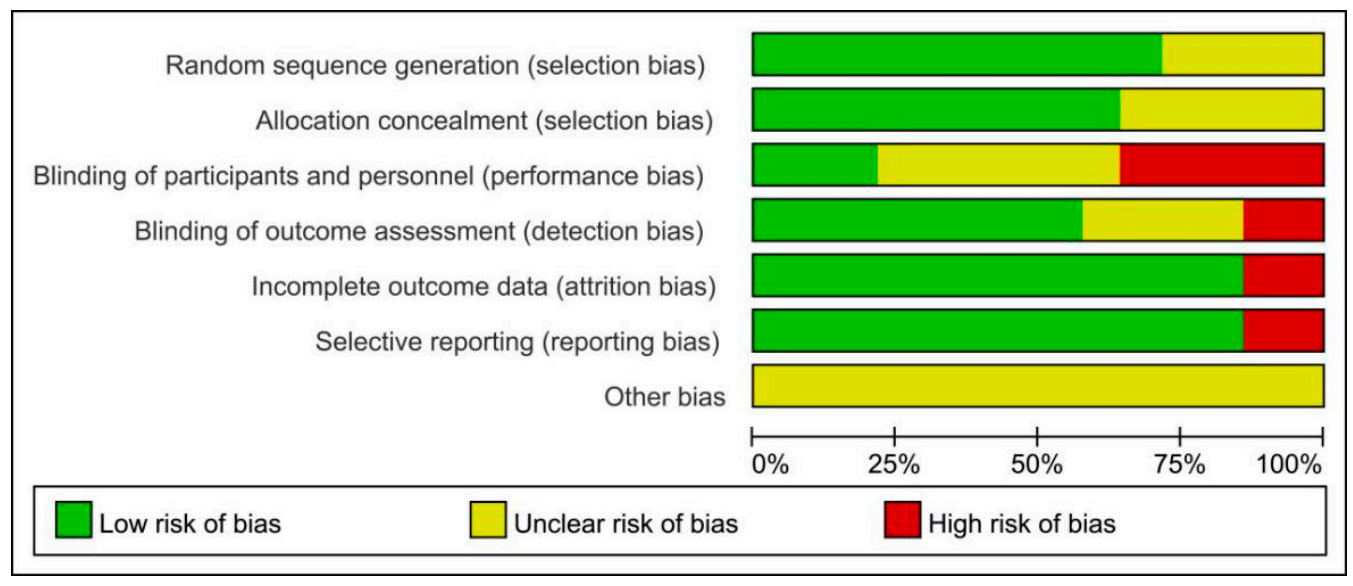

Figure 2. Risk of bias graph.

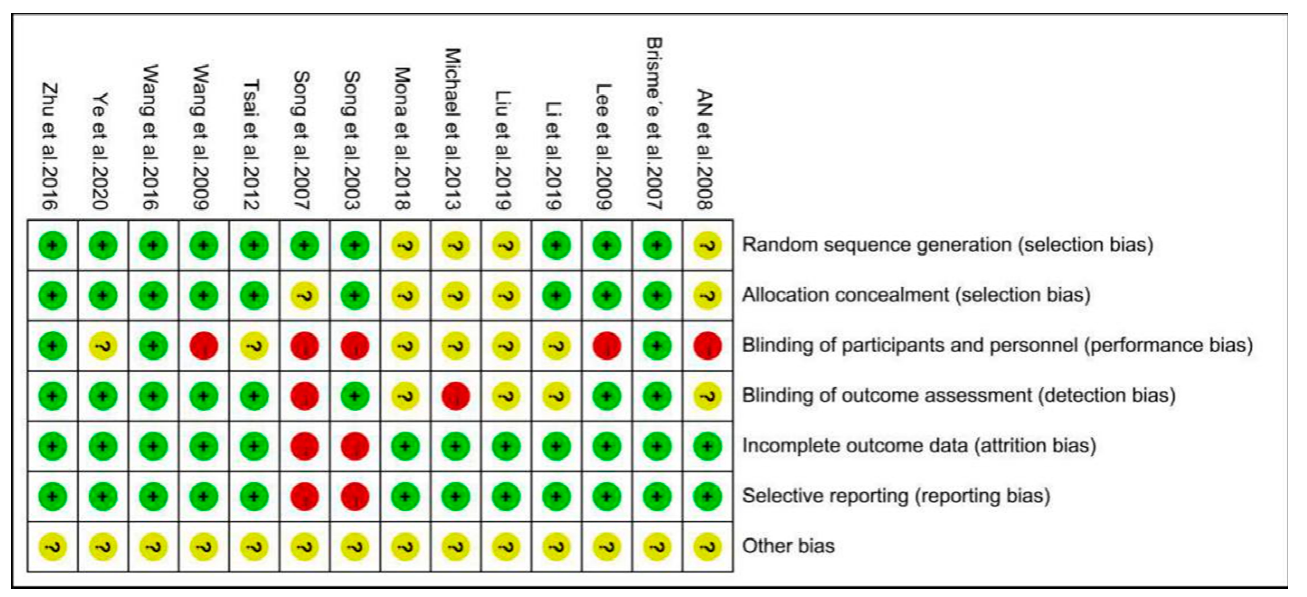

Figure 3. Risk of bias summary. 


\subsection{Outcome Measures}

The findings of the meta-analyses based on 14 included studies are presented by the forest plots in regard to outcomes of pain, stiffness, and physical function using the WOMAC or KOOS score (Figures 4-6). Furthermore, all the included studies used the standardized mean difference (SMD) due to the different questionnaire scale.

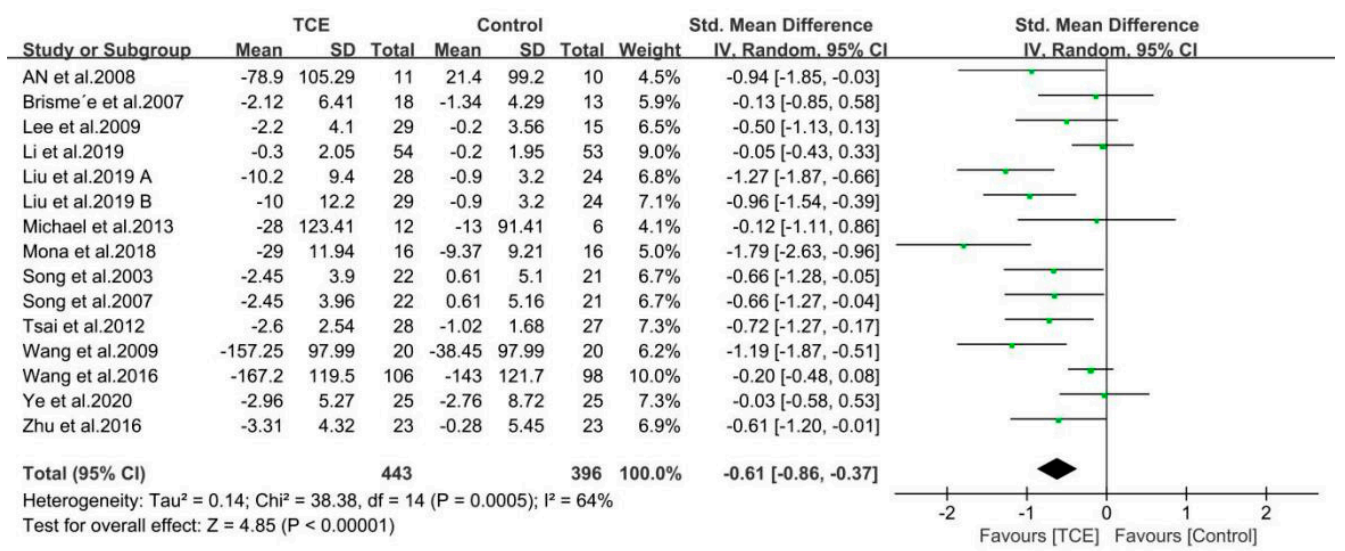

Figure 4. Forest plots showing standardized mean difference of change on the pain score (WOMAC/KOOS) between traditional Chinese exercise (TCE) group and a control/comparison group. CI: Confidence Interval; KOOS: The Knee Injury and Osteoarthritis Outcome Score; WOMAC: The Western Ontario and McMaster Universities Arthritis Index.

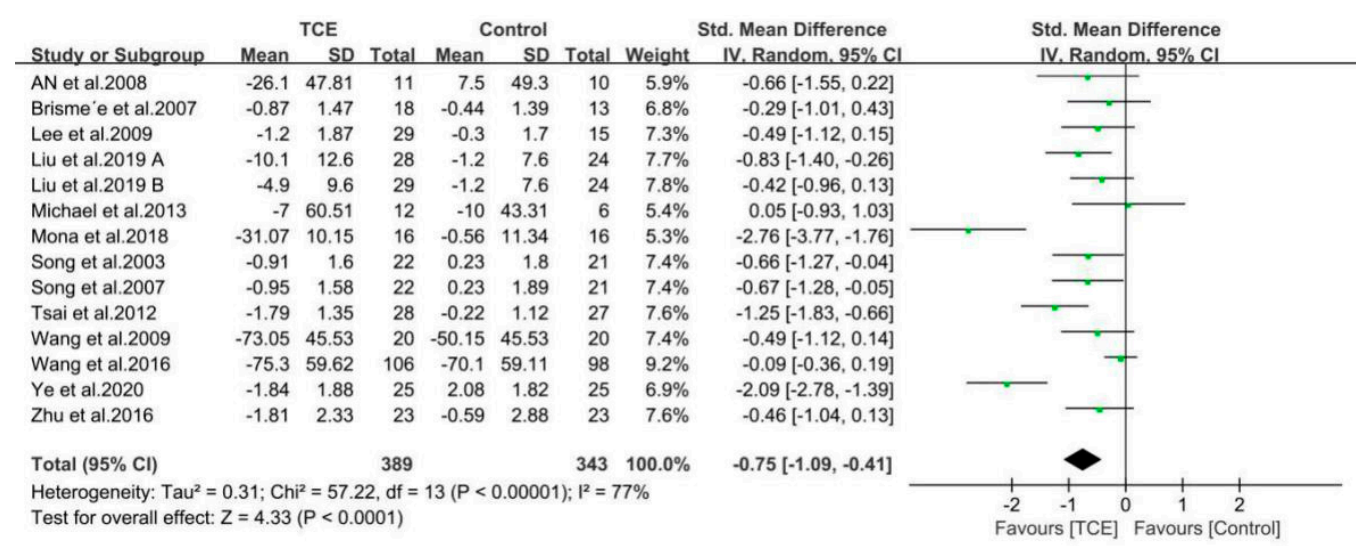

Figure 5. Forest plots showing standardized mean difference of change on the stiffness score (WOMAC/KOOS) between TCE group and a control/comparison group. CI: Confidence Interval; KOOS: The Knee Injury and Osteoarthritis Outcome Score; WOMAC: The Western Ontario and McMaster Universities Arthritis Index. 


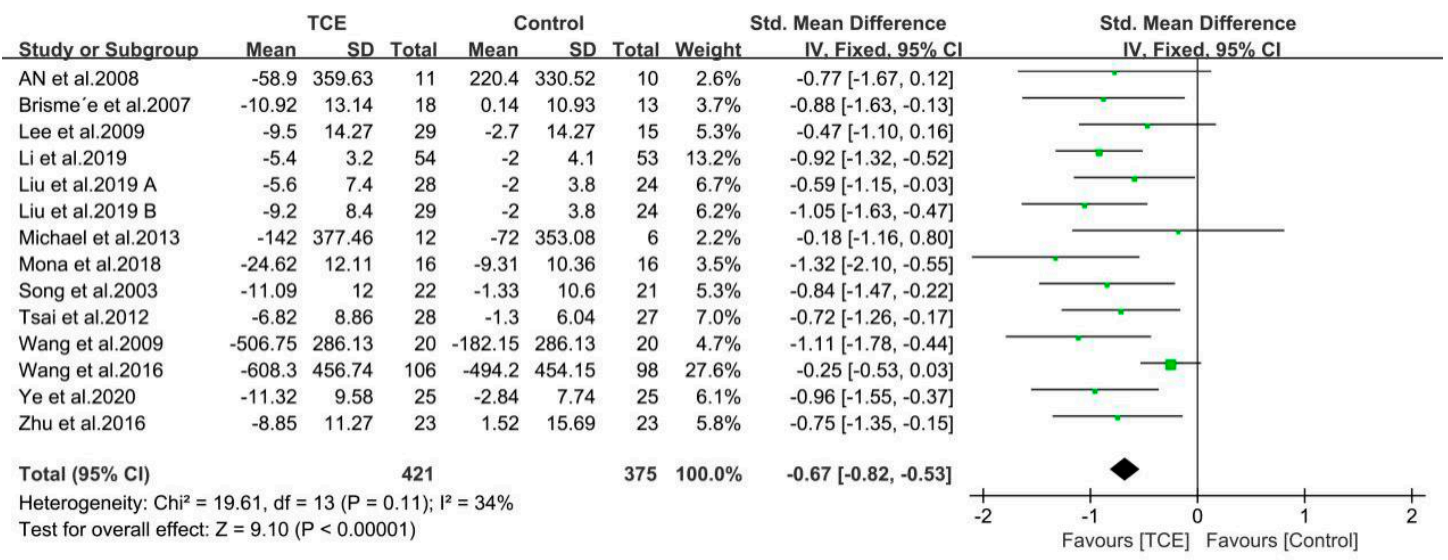

Figure 6. Forest plots showing standardized mean difference of change on the physical function score (WOMAC/KOOS) between TCE group and a control/comparison group. CI: Confidence Interval; KOOS: The Knee Injury and Osteoarthritis Outcome Score; WOMAC: The Western Ontario and McMaster Universities Arthritis Index.

\subsubsection{Pain}

All 14 included studies totaling 815 participants reported the effects of different interventions on outcome of WOMAC/KOOS pain score. The synthesized data indicated that the TCE group had significantly alleviated pain as compared with a control/comparison group (SMD $=-0.61,95 \% \mathrm{CI}$ : -0.86 to $-0.37, p<0.001)$, and there was a substantial heterogeneity for this synthesized outcome $\left(\mathrm{I}^{2}=64 \%\right)$. Therefore, these studies were combined using the random-effects model (Figure 4).

\subsubsection{Stiffness}

A total of 13 studies involving 708 participants reported the effects of different interventions on outcome of WOMAC/KOOS stiffness score [33-37,48,49,51-56]. The synthesized data indicated that the TCE group had effectively relieved stiffness as compared with a control/comparison group $(\mathrm{SMD}=-0.75,95 \% \mathrm{CI}:-1.09$ to $-0.41, p<0.001)$, and there was a high heterogeneity for this synthesized outcome $\left(\mathrm{I}^{2}=77 \%\right)$. Therefore, these studies were combined using the random-effects model (Figure 5 ).

\subsubsection{Physical Function}

There were 13 studies involving 772 participants that reported the effects of different interventions on outcome of WOMAC/KOOS physical function score [33-37,48-53,55,56], The synthesized data indicated that the TCE group benefited far more for improving physical function than a control/comparison group (SMD $=-0.67,95 \% \mathrm{CI}:-0.82$ to $-0.53, p<0.001$ ), and there was a moderate heterogeneity for this synthesized outcome $\left(\mathrm{I}^{2}=34 \%\right)$. Therefore, these studies were combined using the fix-effects model (Figure 6).

\subsection{Evaluation of Publication Bias}

The publication bias of outcome was evaluated using funnel plots based on 14 studies. The funnel plots of the WOMAC/KOOS pain score, WOMAC/KOOS stiffness score, and WOMAC/KOOS physical function score suggested a possible publication bias in small trials, the Egger's test $(P=0.031 ; 0.028$; 0.043) of DCR demonstrated that there was a publication bias. Funnel plots showing a possible publication bias favored the positive studies on outcomes of the WOMAC/KOOS score (Figure 7). It is possible that either their included studies were limited in number, or the negative outcomes did not get published. 
A

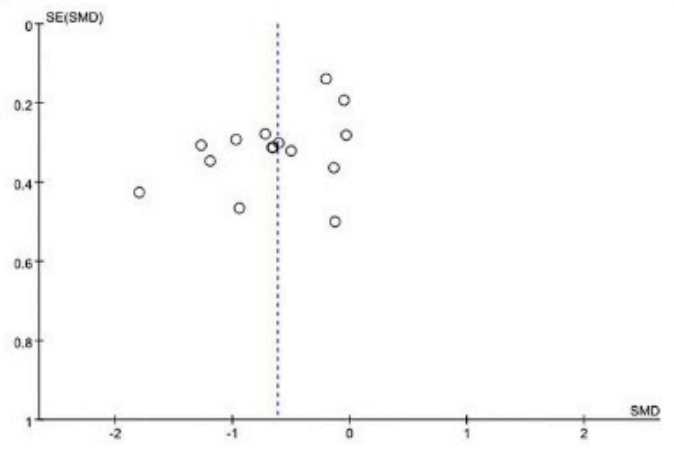

B

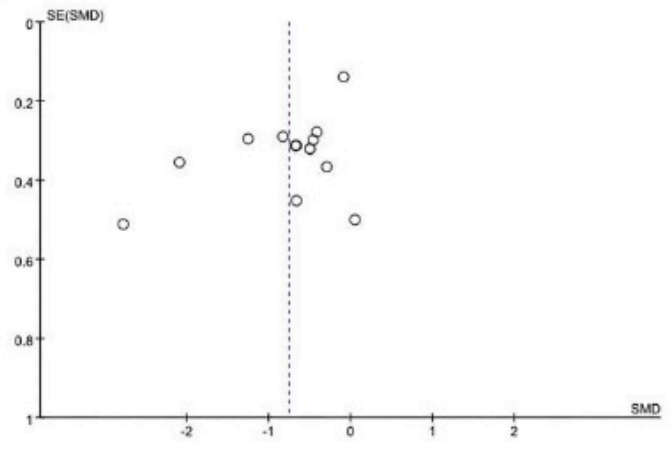

\section{C}

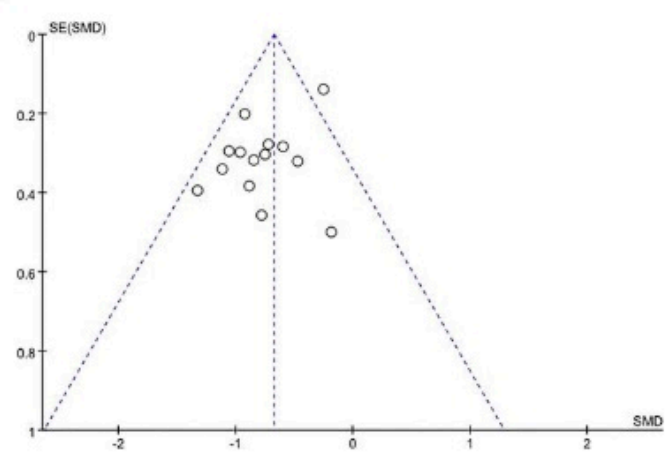

Figure 7. Funnel plots showing a possible publication bias favoring the positive studies on outcomes of the WOMAC/KOOS score. (A) Funnel plots of the WOMAC/KOOS pain score. (B) Funnel plots of the WOMAC/KOOS stiffness score. (C) Funnel plots of the WOMAC/KOOS physical function score.

\subsection{Sensitivity Analysis and Subgroup Meta-Analyses}

\subsubsection{Sensitivity Analysis}

Given the high level of heterogeneity and risk of bias, sensitivity analysis was conducted to identify the robustness of the synthesized outcome. It was performed through removing each individual study. After removing 2 studies $[50,52]$ in pain and 2 studies $[34,52]$ in stiffness respectively, statistical heterogeneity of this synthesized outcome showed dramatically decrease in pain (SMD $=-0.52,95 \% \mathrm{CI}$ : -0.67 to $-0.37, \mathrm{I}^{2}=49 \%$ ) and in stiffness ( $\mathrm{SMD}=-0.43,95 \% \mathrm{CI}:-0.59$ to $-0.28, \mathrm{I}^{2}=39 \%$ ). The reason of high heterogeneity may due to different assessment scale (WOMAC and KOOS).

\subsubsection{Subgroup Meta-Analyses}

Subgroup analyses were performed based on the outcomes of 14 studies, which included exercise type, geographical location, duration time, sample size and control group type. All relevant data of subgroup meta-analyses are shown in Table 2 and the supplementary material (Figures S1-S5).

As shown in the table, we found that except the outcomes of pain in Baduanjin exercise (SMD $=-0.61,95 \% \mathrm{CI}:-1.28$ to $0.06, p=0.07$ ), the outcomes of stiffness in non-Asian populations (SMD $=-0.43,95 \% \mathrm{CI}-0.90$ to $0.04, p=0.08$ ) and the outcomes of symptoms in participant $\leq 30$ (SMD $=-0.43,95 \% \mathrm{CI}:-0.90$ to $0.04, p=0.08)$, the rest of the subgroup analyses indicated significant improvements respectively. 
Table 2. Subgroup meta-analyses.

\begin{tabular}{|c|c|c|c|c|c|c|}
\hline Subgroups & Outcomes & $\begin{array}{l}\text { No. of } \\
\text { Studies }\end{array}$ & $\begin{array}{c}\text { No. of } \\
\text { Sample Size }\end{array}$ & SMD $(95 \%$ CI $)$ & $\begin{array}{l}\text { Statistical } \\
\text { Method }\end{array}$ & $\begin{array}{l}p \text {-Value for } \\
\text { Heterogeneity }\end{array}$ \\
\hline \multicolumn{7}{|l|}{ Exercise type } \\
\hline \multirow[t]{3}{*}{ Tai Chi } & Pain & 12 & 715 & $-0.62[-0.90,-0.34]$ & Random effect & $<0.0001$ ** \\
\hline & Stiffness & 11 & 608 & $-0.67[-1.02,-0.32]$ & Random effect & $0.0002 * *$ \\
\hline & Physical function & 11 & 672 & $-0.62[-0.78,-0.46]$ & Fix effect & $<0.00001^{* *}$ \\
\hline \multirow[t]{3}{*}{ Baduanjin } & Pain & 3 & 124 & $-0.61[-1.28,0.06]$ & Random effect & 0.07 \\
\hline & Stiffness & 3 & 124 & $-1.05[-2.13,0.02]$ & Random effect & $0.05 *$ \\
\hline & Physical function & 3 & 124 & $-0.97[-1.34,-0.59]$ & Fix effect & $<0.00001 * *$ \\
\hline \multicolumn{7}{|l|}{$\begin{array}{l}\text { Geographical } \\
\text { location }\end{array}$} \\
\hline \multirow[t]{3}{*}{$\begin{array}{l}\text { Asian } \\
\text { populations }\end{array}$} & Pain & 9 & 467 & $-0.69[-1.02,-0.36]$ & Random effect & $<0.0001 *$ \\
\hline & Stiffness & 8 & 360 & $-0.94[-1.38,-0.50]$ & Random effect & $<0.0001^{* *}$ \\
\hline & Physical function & 8 & 424 & $-0.85[-1.04,-0.65]$ & Fix effect & $<0.00001 * *$ \\
\hline \multirow{3}{*}{$\begin{array}{l}\text { Non-Asian } \\
\text { populations }\end{array}$} & Pain & 5 & 348 & $-0.47[-0.87,-0.08]$ & Random effect & $0.02 *$ \\
\hline & Stiffness & 5 & 348 & $-0.43[-0.90,0.04]$ & Random effect & 0.08 \\
\hline & Physical function & 5 & 348 & $-0.60[-0.97,-0.22]$ & Random effect & 0.002 ** \\
\hline \multicolumn{7}{|l|}{$\begin{array}{l}\text { Duration } \\
\text { time }\end{array}$} \\
\hline \multirow[t]{3}{*}{8 weeks } & Pain & 2 & 65 & $-0.64[-1.16,-0.12]$ & Fix effect & $0.02 *$ \\
\hline & Stiffness & 2 & 65 & $-0.55[-1.06,-0.03]$ & Fix effect & $0.04 *$ \\
\hline & Physical function & 2 & 65 & $-0.57[-1.09,-0.05]$ & Fix effect & $0.03 *$ \\
\hline \multirow[t]{3}{*}{12 weeks } & Pain & 8 & 599 & $-0.54[-0.85,-0.23]$ & Random effect & $0.0007^{* *}$ \\
\hline & Stiffness & 7 & 492 & $-0.66[-1.06,-0.26]$ & Random effect & $0.001 * *$ \\
\hline & Physical function & 7 & 556 & $-0.78[-1.05,-0.50]$ & Random effect & $<0.00001 * *$ \\
\hline \multirow{4}{*}{$\begin{array}{l}\text { Sample size } \\
\mathrm{n} \geq 30\end{array}$} & & & & & & \\
\hline & Pain & 12 & 776 & $-0.62[-0.89,-0.36]$ & Random effect & $<0.00001 * *$ \\
\hline & Stiffness & 11 & 669 & $-0.81[-1.19,-0.44]$ & Random effect & $<0.0001$ ** \\
\hline & Physical function & 11 & 733 & $-0.68[-0.83,-0.53]$ & Fix effect & $<0.00001 * *$ \\
\hline \multirow[t]{3}{*}{$\mathrm{n}<30$} & Pain & 2 & 39 & $-0.56[-1.23,0.11]$ & Fix effect & 0.1 \\
\hline & Stiffness & 2 & 39 & $-0.34[-1.00,0.31]$ & Fix effect & 0.31 \\
\hline & Physical function & 2 & 39 & $-0.50[-1.17,0.16]$ & Fix effect & 0.13 \\
\hline \multicolumn{7}{|l|}{$\begin{array}{l}\text { Control } \\
\text { group type }\end{array}$} \\
\hline \multirow[t]{3}{*}{$\begin{array}{l}\text { Active } \\
\text { control } \\
\text { group }\end{array}$} & Pain & 8 & 596 & $-0.71[-1.07,-0.35]$ & Random effect & $0.0001 * *$ \\
\hline & Stiffness & 7 & 489 & $-0.74[-1.19,-0.29]$ & Random effect & $0.001 * *$ \\
\hline & Physical function & 8 & 596 & $-0.78[-1.04,-0.52]$ & Random effect & $<0.00001 * *$ \\
\hline \multirow{3}{*}{$\begin{array}{l}\text { Passive } \\
\text { control } \\
\text { group }\end{array}$} & Pain & 6 & 219 & $-0.46[-0.73,-0.18]$ & Fix effect & $0.001 * *$ \\
\hline & Stiffness & 6 & 219 & $-0.78[-1.32,-0.23]$ & Random effect & $0.005 * *$ \\
\hline & Physical function & 5 & 176 & $-0.71[-1.02,-0.40]$ & Fix effect & $<0.00001 * *$ \\
\hline
\end{tabular}

\section{Discussion}

The knee joint, which consists of osseous structures (distal femur, proximal tibia, and patella), cartilages (meniscus and hyaline cartilages), ligaments, and a synovial membrane, is the largest and most complex synovial joint in the human body [57]. Frequent and stressful use of the knee joint may cause serious pain associated with more severe diseases including KOA [58].

$\mathrm{KOA}$ is a degenerative and progressive knee-joint disease with multifactorial etiologies that have been attributed to advancing age, over-weight, female gender, genetic predisposition, trauma, mechanical forces, inflammation, biochemical reactions, and metabolic derangements $[57,59,60]$. The pathophysiology of KOA is characterized by degradation and destruction of cartilage (articular cartilage and subchondral bone) and meniscus, osteophyte formation, bone remodeling, peri-articular muscles weakness, laxity of ligaments and joints, and synovial inflammation. The symptoms of KOA comprise pain, stiffness, swelling, limitation movement, and function impairment of the knee joint $[57,59]$. These may eventually affect the whole joint and eventually lead to disability [4]. Meanwhile, KOA entails chronic inflammation and structural damage unamendable to restoration. Therefore, therapeutic regimens have aimed to improve the symptoms of KOA [57]. 
Currently, an intra-articular injection and cyclooxygenase inhibitors are widely used in the clinical treatment of KOA, such as extended-release triamcinolone acetonide, corticoids (CS), hyaluronic acid (HA), autologous conditioned serum (ACS), platelet-rich plasma (PRP), mesenchymal stem cell (MSC), non-steroidal anti-inflammatory drugs (NSAIDs), and acetaminophen [57,59]. The safety of pharmacological therapies is still a controversy: Patients with KOA are likely to suffer from mild to moderate adverse effects and financial burden [61,62]. Non-pharmacological therapies comprise Tai Chi and other kinds of TCE, yoga, aquatic therapies, and weight loss [15]. Additionally, the majority of studies confirmed that non-pharmacological therapies are safe and highly effective $[15,63,64]$. Hence, they should be administered as the primary treatment option for management of KOA symptoms [57].

Our findings showed significant improvements in pain, stiffness, and physical function with the TCE, which is consistent with results of the first meta-analysis of TCE for KOA performed in 2017 [18]. However, this former meta-analysis has included two ineligible studies, one of them included participants who also had hip osteoarthritis [65], and another study that was retracted due to poor quality [66]. Our meta-analysis conducted more subgroup analyses and included more studies (14 RCTs) and more participants (815), while the previous meta-analysis included only eight studies involving 375 participants.

Our meta-analysis demonstrated that TCE significantly alleviated pain (SMD $=-0.61,95 \%$ CI: -0.86 to $-0.37, p<0.001$ ), relieved stiffness (SMD $=-0.75,95 \% \mathrm{CI}:-1.09$ to $-0.41, p<0.001$ ), and improved physical function (SMD $=-0.67,95 \%$ CI: -0.82 to $-0.53, p<0.001$ ). These benefits are consistent with the results of individual included RCTs [33-37,48-56]. For different exercise types, subgroup analyses indicated there was no statistically significant difference between Tai Chi exercise and Baduanjin exercise in WOMAC/KOOS score. Compared with a control/comparison group, Tai Chi exercise and Baduanjin exercise showed a significant improvement in stiffness score and physical function score. However, in terms of pain, Tai Chi exercise achieved a significant improvement in reducing pain $(p<0.0001)$, while Baduanjin exercise showed no significant difference $(p=0.07)$. This finding may be due to insufficient number of RCTs for the Baduanjin exercise. Therefore, further RCTs are required to investigate the effectiveness of Baduanjin exercise in treating symptoms of KOA.

In addition, several RCTs have evaluated the effectiveness of TCE to other outcomes for patients with KOA. A double-blind randomized clinical trial involving 46 patients demonstrated that Tai Chi could effectively improve gait velocity, step length, and initial contact angle and maximal angle of flexed knees during the stance phase of walking [35]. Another RCT indicated that the Tai Chi group achieved better health behavior after 12 weeks, specifically on a diet behavior and stress management [54]. Meanwhile, a randomized, single-blind, four-arm, clinical trial involving 140 patients demonstrated that the Tai Chi and Baduanjin exercise could significantly relieve pain by simultaneously modulating the resting-state functional connectivity of the descending opioidergic pathway and the dopamine reward/motivation system [51]. There is a single-blind RCT indicating that the Tai Chi group is beneficial for balance and strengthening of the abdominal muscle [53]. Other single-blind RCTs indicated that the Tai Chi/Baduanjin exercise significantly contributed to proprioception and postural stability of the knee joint [34], quadriceps strength [48], self-efficacy [56], depression [33,56], and health-related quality of life $[33,50,56]$. Overall, although the underlying mechanisms of TCE are unknown, it may be an effective treatment regimen for physical and psychological health of patients with KOA.

There are methodological limitations that should be noted. First, all the included RCTs were published in the English language only-this may lead to a language bias, as well as a publication bias that positive results were much more likely reported in journals. However, the English articles are of a much higher quality than the Chinese articles, so only high-quality English articles were included in this study [67-70]. In addition, a publication bias might have existed in the included RCTs since positive trials are more likely to be published than negative results. Second, most of the included RCTs had significant flaws on methodological characteristics. About $70 \%$ of the included RCTs' sample size were less than 30, and some of them lacked concealment of allocation and bias of subjective and report, which could limit the strength of our positive results. Third, the TCE intervention protocol varied 
widely with respect to the exercise type (Tai Chi and Baduanjin), duration time (from 4 to 24 weeks), frequency (two to twelve times per week), and control group that received different interventions. To a certain degree, it is difficult for us to make an optimal training recommendation for health-care professionals and the general public on which type of exercise should be selected, how long the exercise should last, and how frequent the exercise should be. Finally, in some included RCTs, TCE was not mono-therapy to patients but mixed with medicines or usual care, which is hard to confirm whether the positive results were contributed by TCE alone or a synergetic intervention effect (i.e., a combination of TCE and medicines or both TCE and usual care). However, it must be admitted that the improvement of symptoms was achieved in patients with KOA during the TCE intervention period.

\section{Conclusions}

This meta-analysis suggests that TCE may be an effective intervention approach for patients with symptoms of KOA including pain, stiffness, and physical function. Moreover, there are publication and language biases that may overestimate the effectiveness of the TCE intervention. However, without the risk of significant adverse events, clinicians can still consider TCE as an adjuvant therapy incorporating it into their first-line rehabilitation regime for patients with KOA. In addition, given the methodological limitations of the included RCTs in this meta-analysis, which might have impacted the interpretation of these findings, more high-quality RCTs with a large sample size and long-term intervention are required to further confirm the effectiveness and underlying mechanisms of TCE for treating KOA.

Supplementary Materials: The following are available online at http://www.mdpi.com/1660-4601/17/21/7873/s1, Figure S1: Subgroup analyses were performed based on different exercise type. (A) Tai Chi, (B) Baduanjin. Figure S2: Subgroup analyses were performed based on different geographical location. (A) Asian populations, (B) Non-Asian populations. Figure S3: Subgroup analyses were performed based on different duration time. (A) 8 weeks, (B) 12weeks. Figure S4: Subgroup analyses were performed based on different sample size. (A) No. of participants $\geq 30$, (B) No. of participants $<30$. Figure S5: Subgroup analyses were performed based on different control group type. (A) Active control group, (B) Passive control group. Table S1: Search strategy and result of each database.

Author Contributions: Conceptualization, R.L.; methodology, R.L., H.C. and J.F.; software, R.L., H.C. and J.F.; validation, R.L. and H.C.; formal analysis, R.L. and H.C.; investigation, R.L. and H.C.; resources, R.L., H.C., J.F. and H.Z.; data curation, R.L. and H.C.; writing-original draft preparation, R.L., H.C., and J.F.; writing-review and editing, all authors; visualization, R.L. and H.C.; supervision, R.L. and H.X.; project administration, R.L., H.C., J.F. and H.Z.; review and editing, Y.X.; manuscript proof-reading, C.W.-K.L. All authors have read and agreed to the published version of the manuscript.

Funding: This research received no external funding.

Conflicts of Interest: The authors declare no conflict of interest.

\section{Abbreviations}

$\begin{array}{ll}\text { AAOS } & \text { American Academy of Orthopedic Surgeons } \\ \text { ACR } & \text { American College of Rheumatology classification criteria } \\ \text { ACS } & \text { Autologous Conditioned Serum } \\ \text { ARA } & \text { American Rheumatism Association } \\ \text { CG } & \text { Control Group } \\ \text { CI } & \text { Confidence Interval } \\ \text { HA } & \text { Hyaluronic Acid } \\ \text { IG } & \text { Intervention Group } \\ \text { KL } & \text { the Kellgren Lawrence classification } \\ \text { KOA } & \text { Knee Osteoarthritis } \\ \text { KOOS } & \text { the Knee Injury and Osteoarthritis Outcome Score } \\ \text { MSC } & \text { Mesenchymal Stem Cell } \\ \text { NSAIDs } & \text { Non-Steroidal Anti-Inflammatory Drugs } \\ \text { OARSI } & \text { Osteoarthritis Research Society International } \\ \text { PRP } & \text { Platelet-Rich Plasma }\end{array}$




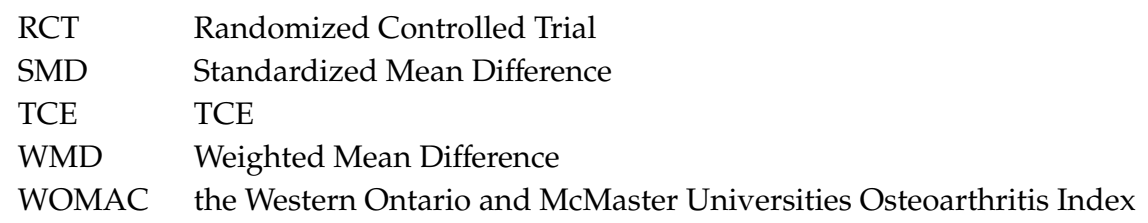

\section{References}

1. World Health Organization (WHO). Chronic Diseases and Health Promotion: Chronic Rheumatic Conditions; World Health Organization: Geneva, Switzerland, 2020; Available online: https:/www.who.int/chp/topics/ rheumatic/en/ (accessed on 20 October 2020).

2. Francisco, V.; Pérez, T.; Pino, J.; López, V.; Franco, E.; Alonso, A.; Gonzalez-Gay, M.A.; Mera, A.; Lago, F.; Gómez, R.; et al. Biomechanics, obesity, and osteoarthritis. The role of adipokines: When the levee breaks. J. Orthop. Res. 2018, 36, 594-604. [CrossRef] [PubMed]

3. Bennell, K.L.; Hunter, D.J.; Paterson, K.L. Platelet-Rich Plasma for the Management of Hip and Knee Osteoarthritis. Curr. Rheumatol. Rep. 2017, 19, 24. [CrossRef] [PubMed]

4. Kolasinski, S.L.; Neogi, T.; Hochberg, M.C.; Oatis, C.; Guyatt, G.; Block, J.; Callahan, L.; Copenhaver, C.; Dodge, C.; Felson, D.; et al. 2019 American College of Rheumatology/Arthritis Foundation Guideline for the Management of Osteoarthritis of the Hand, Hip, and Knee. Arthritis Rheumatol. 2020, 2, 220-233. [CrossRef] [PubMed]

5. Lin, K.W. Treatment of Knee Osteoarthritis. Am. Fam. Physician 2018, 98, 603-606. [PubMed]

6. Silva, G.S.; Sullivan, J.K.; Katz, J.N.; Messier, S.P.; Hunter, D.J.; Losina, E. Long-term clinical and economic outcomes of a short-term physical activity program in knee osteoarthritis patients. Osteoarthr. Cartil. 2020, 28, 735-743. [CrossRef] [PubMed]

7. Aweid, O.; Haider, Z.; Saed, A.; Kalairajah, Y. Treatment modalities for hip and knee osteoarthritis: A systematic review of safety. J. Orthop. Surg. 2018, 26, 2309499018808669. [CrossRef]

8. Kucharz, E.J.; Szántó, S.; Goycheva, M.I.; Petronijević, M.; Šimnovec, K.; Domżalski, M.; Gallelli, L.; Kamenov, Z.; Konstantynowicz, J.; Radunović, G.; et al. Endorsement by Central European experts of the revised ESCEO algorithm for the management of knee osteoarthritis. Rheumatol. Int. 2019, 39, 1117-1123. [CrossRef]

9. Zhao, J.L.; Huang, H.T.; Liang, G.H.; Zeng, L.F.; Yang, W.Y.; Liu, J. Effects and safety of the combination of platelet-rich plasma (PRP) and hyaluronic acid (HA) in the treatment of knee osteoarthritis: A systematic review and meta-analysis. BMC Musculoskelet. Disord. 2020, 21, 224. [CrossRef]

10. Vitali, M.; Ometti, M.; Drossinos, A.; Pironti, P.; Santoleri, L.; Salini, V. Autologous conditioned serum: Clinical and functional results using a novel disease modifying agent for the management of knee osteoarthritis. J. Drug Assess. 2020, 9, 43-51. [CrossRef]

11. Lopa, S.; Colombini, A.; Moretti, M.; Girolamo, L.D. Injective mesenchymal stem cell-based treatments for knee osteoarthritis: From mechanisms of action to current clinical evidences. Knee Surg. Sports Traumatol. Arthrosc. 2019, 27, 2003-2020. [CrossRef]

12. Jung, S.Y.; Jang, E.J.; Nam, S.W.; Kwon, H.H.; Im, S.G.; Kim, D.; Cho, S.K.; Kim, D.; Sung, Y.K. Comparative effectiveness of oral pharmacologic interventions for knee osteoarthritis: A network meta-analysis. Mod. Rheumatol. 2018, 28, 1021-1028. [CrossRef]

13. Sharif, B.; Garner, R.; Hennessy, D.; Sanmartin, C.; Flanagan, W.M.; Marshall, D.A. Productivity costs of work loss associated with osteoarthritis in Canada from 2010 to 2031. Osteoarthr. Cartil. 2017, 25, 249-258. [CrossRef]

14. Park, H.M.; Kim, H.S.; Lee, Y.J. Knee osteoarthritis and its association with mental health and health-related quality of life: A nationwide cross-sectional study. Geriatr. Gerontol. Int. 2020, 20, 379-383. [CrossRef]

15. DeRogatis, M.; Anis, H.K.; Sodhi, N.; Ehiorobo, J.O.; Chughtai, M.; Bhave, A.; Mont, M.A. Non-operative treatment options for knee osteoarthritis. Ann. Transl. Med. 2019, 7. [CrossRef] [PubMed]

16. Bannuru, R.R.; Osani, M.C.; Vaysbrot, E.E.; Arden, N.K.; Bennell, K.; Bierma-Zeinstra, S.M.A.; Kraus, V.B.; Lohmander, L.S.; Abbott, J.H.; Bhandari, M.; et al. OARSI guidelines for the non-surgical management of knee, hip, and polyarticular osteoarthritis. Osteoarthr. Cartil. 2019, 27, 1578-1589. [CrossRef] [PubMed]

17. Meiyappan, K.P.; Cote, M.P.; Bozic, K.J.; Halawi, M.J. Adherence to the American Academy of Orthopaedic Surgeons Clinical Practice Guidelines for Nonoperative Management of Knee Osteoarthritis. J. Arthroplast. 2020, 35, 347-352. [CrossRef] [PubMed] 
18. Zhang, Y.J.; Huang, L.L.; Su, Y.X.; Zhan, Z.G.; Li, Y.N.; Lai, X.Q. The Effects of Traditional Chinese Exercise in Treating Knee Osteoarthritis: A Systematic Review and Meta-Analysis. PLoS ONE 2017, 12, e0170237. [CrossRef]

19. Koh, T.C. Baduanjin-an ancient Chinese exercise. Am. J. Chin. Med. 1982, 10, 14-21. [CrossRef]

20. Guo, Y.; Xu, M.M.; Wei, Z.R.; Hu, Q.C.; Chen, Y.; Yan, J.; Wei, Y.L. Beneficial Effects of Qigong Wuqinxi in the Improvement of Health Condition, Prevention, and Treatment of Chronic Diseases: Evidence from a Systematic Review. Evid. Based Complement. Altern. Med. 2018, 2018. [CrossRef]

21. Wang, X.Q.; Pi, Y.L.; Chen, B.L.; Chen, P.J.; Liu, Y.; Wang, R.; Li, X.; Zhu, Y.; Yang, Y.J.; Niu, Z.B. Effect of traditional Chinese exercise on the quality of life and depression for chronic diseases: A meta-analysis of randomised trials. Sci. Rep. 2015, 5, 15913. [CrossRef]

22. Zeng, Z.P.; Liu, Y.B.; Fang, J.J.; Liu, Y.; Luo, J.; Yang, M. Effects of Baduanjin exercise for knee osteoarthritis: A systematic review and meta-analysis. Complement. Ther. Med. 2020, 48. [CrossRef] [PubMed]

23. Palermi, S.; Sacco, A.M.; Belviso, I.; Marino, N.; Gambardella, F.; Loiacono, C.; Sirico, F. Effectiveness of Tai Chi on Balance Improvement in Type 2 Diabetes Patients: A Systematic Review and Meta-Analysis. J. Aging Phys. Act. 2020. [CrossRef] [PubMed]

24. Zou, L.Y.; Zhang, Y.J.; Sasaki, J.E.; Zou, L.Y.; Zhang, Y.J.; Sasaki, J.E.; Yeung, A.S.; Yang, L.; Loprinzi, P.D.; Sun, J.; et al. Wuqinxi Qigong as an Alternative Exercise for Improving Risk Factors Associated with Metabolic Syndrome: A Meta-Analysis of Randomized Controlled Trials. Int. J. Environ. Res. Public Health 2019, 16, 1396. [CrossRef] [PubMed]

25. Fidan, O.; Seyyar, G.K.; Aras, B.; Colak, E.; Aras, O. The effect of Tai Chi and Qigong on health-related quality of life in Parkinson's disease: A systematic review and meta-analysis of systematic reviews. Int. J. Rehabil. Res. 2019, 42, 196-204. [CrossRef]

26. Wu, B.X.; Ding, Y.N.; Zhong, B.Y.; Jin, X.; Cao, Y.T.; Xu, D.P. Intervention Treatment for Myocardial Infarction with Tai Chi: A Systemic Review and Meta-Analysis. Arch. Phys. Med. Rehabil. 2020. [CrossRef] [PubMed]

27. Reychler, G.; Poncin, W.; Montigny, S.; Luts, A.; Caty, G.; Pieters, T. Efficacy of yoga, tai chi and qi gong on the main symptoms of chronic obstructive pulmonary disease: A systematic review. Respir. Med. Res. 2019, 75, 13-25. [CrossRef]

28. Ding, M.; Wang, C.Y.; Dong, X.S.; Yi, X.R. The Effects of Qigong on Type 2 Diabetes Mellitus: A Systematic Review and Meta-Analysis. Evid. Based Complement. Altern. Med. 2018, 2018. [CrossRef]

29. Zou, L.Y.; Zhang, Y.J.; Yang, L.; Loprinzi, P.D.; Yeung, A.S.; Kong, J.; Chen, K.W.; Song, W.; Xiao, T.; Li, H. Are Mindful Exercises Safe and Beneficial for Treating Chronic Lower Back Pain? A Systematic Review and Meta-Analysis of Randomized Controlled Trials. J. Clin. Med. 2019, 8, 628. [CrossRef]

30. Zeng, Y.C.; Xie, X.H.; Cheng, A.S.K. Qigong or Tai Chi in Cancer Care: An Updated Systematic Review and Meta-analysis. Curr. Oncol. Rep. 2019, 21, 48. [CrossRef]

31. Ge, L.; Zheng, Q.X.; Liao, Y.T.; Tan, J.Y.; Xie, Q.L.; Rask, M. Effects of traditional Chinese exercises on the rehabilitation of limb function among stroke patients: A systematic review and meta-analysis. Complement. Ther. Clin. Pract. 2017, 29, 35-47. [CrossRef]

32. Lauche, R.; Langhorst, J.; Dobos, G.; Cramer, H. A systematic review and meta-analysis of Tai Chi for osteoarthritis of the knee. Complement. Ther. Med. 2013, 21, 396-406. [CrossRef]

33. Wang, C.C.; Schmid, C.H.; Iversen, M.D.; Harvey, W.F.; Fielding, R.A.; Driban, J.B.; Price, L.L.; Wong, J.B.; Reid, K.F.; Rones, R.; et al. Comparative Effectiveness of Tai Chi Versus Physical Therapy for Knee Osteoarthritis: A Randomized Trial. Ann. Intern. Med. 2016, 165, 77-86. [CrossRef] [PubMed]

34. Ye, J.J.; Simpson, M.W.; Liu, Y.; Lin, W.; Zhong, W.H.; Cai, S.H.; Zou, L.Y. The Effects of Baduanjin Qigong on Postural Stability, Proprioception, and Symptoms of Patients with Knee Osteoarthritis: A Randomized Controlled Trial. Front. Med. 2020, 6, 307. [CrossRef] [PubMed]

35. Zhu, Q.G.; Huang, L.Y.; Wu, X.; Wang, L.; Zhang, Y.Y.; Fang, M.; Liu, Y.; Li, J.X. Effects of Tai Ji Quan training on gait kinematics in older Chinese women with knee osteoarthritis: A randomized controlled trial. J. Sport Health Sci. 2016, 5, 297-303. [CrossRef]

36. Lee, H.J.; Park, H.J.; Chae, Y.; Kim, S.Y.; Kim, S.N.; Kim, S.T.; Kim, J.H.; Yin, C.S.; Lee, H. Tai Chi Qigong for the quality of life of patients with knee osteoarthritis: A pilot, randomized, waiting list controlled trial. Clin. Rehabil. 2009, 23, 504-511. [CrossRef] [PubMed] 
37. Wortley, M.; Zhang, S.N.; Paquette, M.; Byrd, E.; Baumgartner, L.; Klipple, G.; Krusenklaus, J.; Brown, L. Effects of resistance and Tai Ji training on mobility and symptoms in knee osteoarthritis patients. J. Sport Health Sci. 2013, 2, 209-214. [CrossRef]

38. Shamseer, L.; Moher, D.; Clarke, M.; Ghersi, D.; Liberati, A.; Petticrew, M.; Shekelle, P.; Stewart, L.A. Preferred reporting items for systematic review and meta-analysis protocols (PRISMA-P) 2015: Elaboration and explanation. BMJ 2015, 350, 1. [CrossRef]

39. Damen, J.; Rijn, R.M.V.; Emans, P.J.; Hilberdink, W.K.H.A.; Wesseling, J.; Oei, E.H.G.; Bierma-Zeinstra, S.M.A. Prevalence and development of hip and knee osteoarthritis according to American College of Rheumatology criteria in the CHECK cohort. Arthritis Res. Ther. 2019, 21, 4. [CrossRef]

40. Altman, R.; Asch, E.; Bloch, D.; Bole, G.; Borenstein, D.; Brandt, K.; Christy, W.; Cooke, T.D.; Greenwald, R.; Hochberg, M.; et al. Development of criteria for the classification and reporting of osteoarthritis. Classification of osteoarthritis of the knee. Diagnostic and Therapeutic Criteria Committee of the American Rheumatism Association. Arthritis Rheumatol. 1986, 29, 1039-1049. [CrossRef]

41. Schiphof, D.; Klerk, B.M.D.; Kerkhof, H.J.M.; Hofman, A.; Koes, B.W.; Boers, M.; Bierma-Zeinstra, S.M.A. Impact of different descriptions of the Kellgren and Lawrence classification criteria on the diagnosis of knee osteoarthritis. Ann. Rheum. Dis. 2011, 70, 1422-1427. [CrossRef]

42. Gandek, B. Measurement properties of the Western Ontario and McMaster Universities Osteoarthritis Index: A systematic review. Arthritis Care Res. 2015, 67, 216-229. [CrossRef] [PubMed]

43. Collins, N.J.; Prinsen, C.A.C.; Christensen, R.; Bartels, E.M.; Terwee, C.B.; Roos, E.M. Knee Injury and Osteoarthritis Outcome Score (KOOS): Systematic review and meta-analysis of measurement properties. Osteoarthr. Cartil. 2016, 24, 1317-1329. [CrossRef] [PubMed]

44. Guo, L.J.; Kong, Z.W.; Zhang, Y.J. Qigong-Based Therapy for Treating Adults with Major Depressive Disorder: A Meta-Analysis of Randomized Controlled Trials. Int. J. Environ. Res. Public Health 2019, 16, 826. [CrossRef] [PubMed]

45. Higgins, J.P.T; Altman, D.G.; Sterne, J.A.C. Chapter 8: Assessing risk of bias in included studies. In Cochrane Handbook for Systematic Reviews of Interventions; Version 5.1.0; Higgins, J.P.T., Green, S., Eds.; The Cochrane Collaboration: London, UK, 2011; Available online: www.cochrane-handbook.org (accessed on 20 October 2020).

46. Deeks, J.J.; Higgins, J.P.T.; Altman, D.G. Chapter 9: Analysing data and undertaking Meta-analyses. In Cochrane Handbook for Systematic Reviews of Interventions; Version 5.1.0; Higgins, J.P.T., Green, S., Eds.; The Cochrane Collaboration: London, UK, 2011; Available online: www.cochrane-handbook.org (accessed on 20 October 2020).

47. Riley, R.D.; Higgins, J.P.; Deeks, J.J. Interpretation of random effects meta-analyses. BMJ 2011, 10, 342-549. [CrossRef] [PubMed]

48. An, B.C.; Dai, K.R.; Zhu, Z.A.; Wang, Y.; Hao, Y.Q.; Tang, T.T.; Yan, H.Q. Baduanjin alleviates the symptoms of knee osteoarthritis. J. Altern. Complement. Med. 2008, 14, 167-174. [CrossRef]

49. Brismée, J.M.; Paige, R.L.; Chyu, M.C.; Boatright, J.D.; Hagar, J.M.; McCaleb, J.A.; Quintela, M.M.; Feng, D.; Xu, K.T.; Shen, C.L. Group and home-based tai chi in elderly subjects with knee osteoarthritis: A randomized controlled trial. Clin. Rehabil. 2007, 21, 99-111. [CrossRef]

50. Li, L.T.; Cheng, S.H.; Wang, G.D.; Duan, G.Q.; Zhang, Y.M. Tai chi chuan exercises improve functional outcomes and quality of life in patients with primary total knee arthroplasty due to knee osteoarthritis. Complement. Ther. Clin. Pract. 2019, 35, 121-125. [CrossRef]

51. Liu, J.; Chen, L.D.; Chen, X.L.; Hu, K.; Tu, Y.X.; Lin, M.Q.; Huang, J.; Liu, W.L.; Wu, J.S.; Qiu, Z.J.; et al. Modulatory effects of different exercise modalities on the functional connectivity of the periaqueductal grey and ventral tegmental area in patients with knee osteoarthritis: A randomised multimodal magnetic resonance imaging study. Br. J. Anaesth. 2019, 123, 506-518. [CrossRef]

52. Nahayatbin, M.; Ghasemi, M.; Rahimi, A.; Khademi, K.; Naimi, S.; Tabatabaee, S.M.; Zarein, D.S. The Effects of Routine Physiotherapy Alone and in Combination with Either Tai Chi or Closed Kinetic Chain Exercises on Knee Osteoarthritis: A Comparative Clinical Trial Study. Iran. Red Crescent Med. J. 2018, 20. [CrossRef]

53. Song, R.; Lee, E.O.; Lam, P.; Bae, S.C. Effects of tai chi exercise on pain, balance, muscle strength, and perceived difficulties in physical functioning in older women with osteoarthritis: A randomized clinical trial. J. Rheumatol. 2003, 30, 2039-2044. 
54. Song, R.; Lee, E.O.; Lam, P.; Bae, S.C. Effects of a Sun-style Tai Chi exercise on arthritic symptoms, motivation and the performance of health behaviors in women with osteoarthritis. J. Korean Acad. Nurs. 2007, 37, 249-256. [CrossRef]

55. Tsai, P.F.; Chang, J.Y.; Beck, C.; Kuo, Y.F.; Keefe, F.J. A pilot cluster-randomized trial of a 20-week Tai Chi program in elders with cognitive impairment and osteoarthritic knee: Effects on pain and other health outcomes. J. Pain Symptom Manag. 2013, 45, 660-669. [CrossRef] [PubMed]

56. Wang, C.C.; Schmid, C.H.; Hibberd, P.L.; Kalish, R.; Roubenoff, R.; Rones, R.; McAlindon, T. Tai Chi is effective in treating knee osteoarthritis: A randomized controlled trial. Arthritis Rheumatol. 2009, 61, 1545-1553. [CrossRef] [PubMed]

57. Mora, J.C.; Przkora, R.; Cruz-Almeida, Y. Knee osteoarthritis: Pathophysiology and current treatment modalities. J. Pain Res. 2018, 11, 2189-2196. [CrossRef] [PubMed]

58. Richebé, P.; Capdevila, X.; Rivat, C. Persistent Postsurgical Pain: Pathophysiology and Preventative Pharmacologic Considerations. Anesthesiology. 2018, 129, 590-607. [CrossRef]

59. Heidari, B. Knee osteoarthritis prevalence, risk factors, pathogenesis and features: Part I. Casp. J. Intern. Med. 2011, 2, 205-212.

60. Andriacchi, T.P.; Favre, J.; Erhart-Hledik, J.C.; Chu, C.R. A systems view of risk factors for knee osteoarthritis reveals insights into the pathogenesis of the disease. Ann. Biomed. Eng. 2015, 43, 376-387. [CrossRef]

61. Oo, W.M.; Liu, X.Q.; Hunter, D.J. Pharmacodynamics, efficacy, safety and administration of intra-articular therapies for knee osteoarthritis. Expert Opin. Drug Metab. Toxicol. 2019, 15, 1021-1032. [CrossRef]

62. Hiligsmann, M.; Cooper, C.; Arden, N.; Boers, M.; Branco, J.C.; Brandi, M.L.; Bruyère, O.; Guillemin, F.; Hochberg, M.C.; Hunter, D.J.; et al. Health economics in the field of osteoarthritis: An expert's consensus paper from the European Society for Clinical and Economic Aspects of Osteoporosis and Osteoarthritis (ESCEO). Semin. Arthritis Rheum. 2013, 43, 303-313. [CrossRef]

63. Liu, B.Y.; Fan, Z.; Wang, Z.Y.; Li, M.; Lu, T. The efficacy and safety of Health Qigong for ankylosing spondylitis: Protocol for a systematic review and meta-analysis. Medicine 2020, 99. [CrossRef]

64. Lu, M.L.; Su, Y.X.; Zhang, Y.J.; Zhang, Z.Y.; Wang, W.T.; He, Z.; Liu, F.W.; Li, Y.N.; Liu, C.Y.; Wang, Y.R.; et al. Effectiveness of aquatic exercise for treatment of knee osteoarthritis: Systematic review and meta-analysis. $Z$. Rheumatol. 2015, 74, 543-552. [CrossRef] [PubMed]

65. Fransen, M.; Nairn, L.; Winstanley, J.; Lam, P.; Edmonds, J. Physical activity for osteoarthritis management: A randomized controlled clinical trial evaluating hydrotherapy or Tai Chi classes. Arthritis Care Res. 2007, 57, 407-414. [CrossRef] [PubMed]

66. Ni, G.X.; Song, L.; Yu, B.; Huang, C.H.; Lin, J.H. Tai chi improves physical function in older Chinese women with knee osteoarthritis: Retraction. J. Clin. Rheumatol. 2010, 16, 64-67. [CrossRef] [PubMed]

67. Wu, Q.; Yao, X.; Chen, H.; Liu, Z.; Li, T.; Fan, X.; Zhang, G.; Yu, L.; Chen, M.; Xu, C.; et al. Long-term aspirin use for primary cancer prevention: An updated systematic review and subgroup meta-analysis of 29 randomized clinical trials. J. Cancer 2020, 11, 6460-6473. [CrossRef]

68. Chen, H.; Yao, X.; Li, T.; Lam, C.W.; Zhang, R.; Zhang, H.; Wang, J.; Zhang, W.; Leung, E.L.; Wu, Q. Compound Kushen injection combined with platinum-based chemotherapy for stage III/IV non-small cell lung cancer: A meta-analysis of 37 RCTs following the PRISMA guidelines. J. Cancer 2020, 11, 1883-1898. [CrossRef] [PubMed]

69. Chen, H.; Yao, X.; Li, T.; Lam, C.W.; Zhang, R.; Zhang, H.; Wang, J.; Zhang, W.; Leung, E.L.; Wu, Q. Compound Kushen injection plus platinum-based chemotherapy for stage IIIB/IV non-small cell lung cancer: A protocol for meta-analysis of randomized clinical trials following the PRISMA guidelines. Medicine 2019, 98. [CrossRef]

70. Wu, Q.; Chen, H.; Yao, X.; Li, T.; Xu, C.; Wang, J.; Sui, X.; Leung, E.L. Long-term aspirin use for cancer primary prevention: A protocol for updated systematic review and subgroup meta-analysis of randomized clinical trials. Medicine 2019, 98. [CrossRef]

Publisher's Note: MDPI stays neutral with regard to jurisdictional claims in published maps and institutional affiliations. 